\title{
Analysing e-Learning and Modern Learning Environments
}

\author{
Seppo J. Sirkemaa
}

\begin{abstract}
Advancements in information technology have made available tools that allow learning to take place anytime and anywhere. The changes in technology demand changes in the way education is being arranged as well. The answer has been increased involvement of information technology in all stages of the learning process, which has been known as e-Learning, or more recently as m-Learning. The discussion around e-Learning and $\mathrm{m}$-Learning reflects the skills needed in the modern labour market, and it highlights the importance of technology in the modern society. Consequently, there are significant pressures to develop learning environments that use modern technology. With all technology and portable devices available today, are we already in modern learning environments?
\end{abstract}

Index Terms - E-learning, m-learning, learning environment, modern learning, education.

\section{INTRODUCTION}

With information technology (IT) it is possible to work and study from a distance. Today it has been widely acknowledged that learning can happen also in other places than traditional classroom. The key issue in learning is direct interaction between teachers, students and student groups and this interaction should be powered with information technology [1].

\section{Potential of E-Learning}

In general, e-learning is the future of education. As "traditional" education is bound to classrooms, e-learning makes it possible to study regardless of time and space. It may also provide new groups of students opportunities that are not available with other forms of education. The impact of e-learning on adult education - for example - is significant. In addition, courses can be provided both locally and nationally as well as on the global market.

Technology may support learning in several ways starting from information delivery and ending with cognitive tools in the learning process [2]. In information delivery is technology used primarily in accessing and delivering information, which is stored and categorized into digital format.

As an example, the information system in a library may be seen as an information delivery system At the other end of the continuum are cognitive tools. They refer to technology or systems that are primarily developed to support and improve

Manuscript received August 25, 2013; revised November 11, 2013.

Seppo J. Sirkemaa is with University of Turku, Finland. He works currently at University Consortium of Pori, Finland and is off duty from Turku University of Applied Sciences, Turku, Finland (e-mail:seppo.sirkemaa@utu.fi). the learning process [1]. Blackboard is a known example of technology that has been developed to this purpose.

The role of technology varies greatly in modern learning environments. In most cases courses are provided partly as traditional learning, partly as online education. This is referred to as "mixed mode" education. However, there are also on-line courses or degrees that are almost completely digital. As a result, e-learning is a multifaceted issue, and the term can be used in different contexts. e-learning has significant potential in workplace, in empowering teamwork and combining different disciplines: economics, management, technological, environmental and social studies [3].

With current technology internationalization of individual studies is relatively easy: technology helps in meeting new people, exchanging ideas between individual students and student groups, and it empowers communication between teachers and researchers in the international education community. Modern learning environments change also the role of teachers and students. The role of the teacher will be to motivate and facilitate learning, whereas the student is expected to adopt an active role in the learning process.

To summarize, e-learning is seen as a solution to geographical, physical or time-related barriers to accessing education. Information technology, networks and digital communication make crossing boundaries between schools nationally and internationally easier than ever.

\section{MobILITY IN EDUCATION}

There is an increasing demand for education that does not happen solely in a classroom. For example adults have difficulties or find it impossible to study in courses that are arranged during normal business hours. Instead, they prefer studying in the evening or at weekends. Also the physical barriers, such as disability of the student as well as the physical limitations of learning space or classroom size may be overcome by using information technology.

As our lifestyle has become more mobile and uses information technology widely, it is natural to expect solutions that enable studying from a distance. In an ideal case studying could be possible at each students own pace whenever appropriate to the student. As a result, courses should be organized so that they meet the needs of mobile learners. It is a question of changing the educational paradigm.

What is mobility? Typically, mobility refers to a user carrying a portable terminal device that connects to the network with wireless connection. Mobility can be divided into three main classes [4]:

- terminal mobility.

- personal mobility. 
- service portability.

Terminal mobility refers to technologies and devices that enable mobile access from any location. In this case user's terminal must be within the range of the wireless networking technology in order to be connected. For example, laptop computers that are connected with wireless local area network (WLAN) are online only within the coverage area of the wireless access point. In addition, the communications settings of the laptop computers must be set so that they connect to the appropriate network. This illustrates that terminal mobility requires also that the network or service that is being accessed is able to identify the mobile terminal.

Personal mobility refers to users need to connect while traveling - the user should be able to access telecommunication services from any location. On the other hand, personal mobility means also that it must be possible to contact a mobile user, wherever he or she might be.

It is important to notice that both wireless and wired technology can be used in connecting a user. The emphasis is on the user who can decide which terminal and technology to use at a given location to be connected. For example, the user may use a wired connection if it is available because it may offer more bandwidth than a wireless terminal. As a result, in most real-life cases both wireless and wired technology are used to provide best possible personal mobility to a mobile user.

Service portability is about the services that are being accessed through a mobile terminal. This is a challenge for service providers. The goal is that the services can be used with different terminal devices. They range from laptop computers to different tablet computers, and smartphones. These devices run with different operating systems and operating system versions - which should be supported. For example, application made for devices running with Android operating system do not run on Apple devices unless the application developers releases an Apple version. Furthermore, there are limitations made by operating system versions. The bandwidth of the connections may vary substantially. The task of the content providers and service developers is challenged further by the fact that the user may move to a location where there is lots of interference, and the terminal should be able to gracefully reconnect in case the signal would be lost completely.

\section{THE NEED FOR CHANGES}

Ideally, technology should add value to the learning process but not act in a center role [5]. Therefore, even more important than technology is the question of pedagogical changes in modern learning environments.

Generally, the role of information technology in learning is characterized [5]:

- The use of student-centered technology: information technology is used in different activities rather than in passing on content

- Realism: a great deal of importance is placed on providing tasks that are as realistic as possible

- Technology is seen as a tool that mediates in learning,

- and virtual learning environments should be analysed within the context of social change and evolution
In modern learning environments the emphasis is on the student: he or she should use information technology as a tool in the learning process. Learning is an active, constructive process [1]. Therefore, the learner is supposed to utilize technology actively to gather and process data. Here we look at issues that need to be taken into account when adapting education to mobile environments.

Technology should be used - or adapted - in a way that it supports the learning processes in the best possible way. This makes adaptation a key issue in modern learning environments. Generally, adaptation can be classified into two main categories [6]: adaptation to the client device and adaptation to user's behavior.

The first type of adaptation refers to portability, it is manifested in the flexibility to use different hardware platforms, operating systems and user devices. For example, the same material might be accessible with a desktop computer and a PDA, even though the screen size and input devices would be different. Today one of the most popular methods in maximizing the flexibility to adapt to different devices in WWW- based learning environments is to make the material using XML-standard [7].

Adaptation to user's behavior means that the system should fulfill user's expectations. This type of "a priori" knowledge may not be available, and therefore adaptation to user's behavior is often based on user input. In this case facts about the user are gathered and analyzed so that users can be categorized and the content customized to each group of users [8].

It is important to notice that technology - and the learning environment - should adapt to different learners and learning strategies, not vice versa. In a simple environment the user can get frustrated and the motivation to use the environment falls. On the other hand, in a complex environment or in a system where navigation is not straightforward the user may be lost and confused. In real life one learner will find the environment easy to use whereas other considers it difficult to use. Therefore adapting the learning environment to learners with different skills may be one of the greatest challenges [9].

For lecturers adaptation involves more than changing course material to digital format. Information technology makes it possible to stay in touch with students anywhere and anytime, it offers more than tools for writing or sending email. However, the pedagogical aspects may remain unchanged, and placing course material into the web is often considered as the most important issue in creating a modern learning environment. Especially in m-Learning this is not enough; the learners are using portable terminal devices and access the material from locations where connection can suffer from low bandwidth, for example. These conditions need to be addressed in developing the learning environment.

The pedagogical goals in traditional and modern learning environments are the same, but the range of pedagogical and didactical possibilities is different. Empirical experiences reveal that development of modern learning environments makes it possible to rethink the roles of students and teachers. In many cases the result has been a change from lecturing towards tutoring and mentoring, and the students have adopted a far more active role as learners. Ideally, when 
technology is involved in learning the goal should be that the learning experience would be better than in traditional education.

\section{NEW SKILLS NEEDED IN E-LEARNING}

Modern learning environments present challenges for both students and lecturers. Apparently, information technology in education is a challenge for teachers. It involves changing material to digital format. Furthermore, teachers should be able to use different computers and terminals, and understand the limitations that current technology imposes. Especially in mobile environment there are several problems that make the use of terminal devices complicated (low bandwidth, small screen and keyboard, short battery-life etc.). Teachers should also know how to use different software when preparing material to the learning environment. Obviously, skills in using IT are in a critical role, and therefore teachers need guidance and support.

There are several challenges for students as well. Firstly, learning is an active process in modern learning environments. Old studying methods and attitudes have to be changed - sitting in a classroom is not enough. The student must actively seek information and process it using technology that is available as a tool in this process. Secondly, the student must be able and willing to use technology. It is also important to adapt to changing technological environment. For example, technology may work unreliably, and often the learner must find a way to solve the problem alone. Despite this students need to be able to connect to the learning environment.

As noted above, the role of information technology is critical in modern learning environments. Ideally, most of the teaching material is in digital format and each student can access it with a mobile terminal. Discussion and feedback between teachers and students relies on telecommunications. When information technology and networks have such a central role in the learning process, skills in using IT are becoming increasingly critical.

If students are not familiar with technology, it may be overwhelming to manage the environment. For example, there are numerous settings that must be set in order to connect from a mobile terminal to the network.

On the other hand, also teachers have to master technology and understand the limitations of the infrastructure. Consequently, the role of students and teachers is changing in modern learning environments.

\section{DISCUSSION}

Learning is necessary for us as individuals and as society, in developing as individuals, organizations and humanity to find something better [10]. Knowledge and skills in using computers, networks and collaborative technologies are essential in the digital age. The access-point for education is the learning environment, which is often a virtual learning-space. For example, the evaluation and feedback of student's exercises is not necessarily limited to a certain time or place. Information technology and networks are in a critical role as access to information takes place with computers. Education is becoming more mobile as both students and lecturers can connect to the learning material from distance.

The pace of technological innovation and change continues as ever smaller, and lighter, portable terminal devices are being introduced. Shortly, these devices and technologies make it possible to log in and keep in touch anytime and anywhere. The result is that learning can take place wherever the student is roaming - also mobile learners can keep in touch with the learning material and other learners while traveling, for example. However, it can be questioned what mobility means in education. In a typical case no real mobility exists, because in most courses students still travel to lecturers and libraries. Only some parts of the course material may be accessed with a computer, or information technology is used as a tool to send exercises, ask for advice etc. Both the student and the lecturer sit behind a traditional "wired" computer when they are doing this. A truly mobile student or lecturer who is connected while travelling is a rare case.

The explanation why mobility in education is not more widespread is due to general problems that are result of mobile environment rather than e-learning. For example, battery problems and high costs are obstacles for mobile use of information technology. Especially for students the costs of terminal equipment and communications expenses are often too high.

This does not necessarily mean that e-learning has failed to satisfy the needs of a mobile user, a student or a lecturer. More and more learning environments take advantage of information technology and are built to a WWW-format or they connect to Internet using WWW-interface. Consequently, an arbitrary computer that can connect to the Internet and is able to run a WWW-browser can be used for ubiquitous access. Furthermore, with existing technology people from opposite parts of the globe can work together in developing the learning environment, for example in preparing courses to international students.

Modern learning environments can diversify the student body and contribute to expanding the learning experience for all people who are involved in the learning process. Developers of modern learning environment should focus how the user manages technology that is constantly changing and requires the user to learn new technical skills in order to work with technology. The environment needs to be as easy to navigate as possible, and it should address the needs of differently skilled users and their learning styles. Whereas lecturers are concerned the pedagogical opportunities and challenges that IT presents need to be explored.

\section{REFERENCES}

[1] D. H. Jonassen, T. Reeves, N. Hong, D. Harvey, and K. Peters, "Concept mapping as cognitive learning and assessment tools," Journal of Interactive Learning Research, vol. 8, no. 3, pp. 289-308, 1997.

[2] T. C. Reeves and J. Laffey, "Design, assessment, and evaluation of a problem-based learning environment in undergraduate engineering," Higher Education Research \& Development, vol. 18, no. 2, pp. 219-232, 1999.

[3] L. Basil, Business Games for Management and Economics: Learning by Playing, Singapore: World Scientific Publishing Company, Inc., 2012. 
[4] R. Pandya, "Emerging mobile and personal communication systems," IEEE Communications Magazine, vol. 33, pp. 44-52, June 1995.

[5] B. Gros, "Knowledge construction and technology," Journal of Educational Multimedia and Hypermedia, vol. 11, no. 4, pp. 323-343, 2002.

[6] P. Brusilovsky, "Adaptive Hypermedia," User Modeling and User-Adapted Interaction, vol. 11, pp. 87-110, 2001.

[7] F. Wehner and A. Lorz, "Developing modular and adaptable courseware using teachml," in Proc. ED-MEDIA, 2001, pp. 2013-2018.

[8] E. Rich, "User Modeling via Stereotypes," in M. T. Maybury and W. Wahlster, (Eds.), Readings in Intelligent User Interfaces, San Francisco: Morgan Kaufmann Publishers Inc, California, 1998.

[9] J. Raskin, "The Human Interface," New Directions for Designing Interactive Systems, Massachusetts: Addison-Wesley Longman Inc, 2000.
[10] P. Jarvis, "Democracy," Lifelong Learning and the Learning Society: Active Citizenship in a Late Modern Age, London: Routledge, 2008.

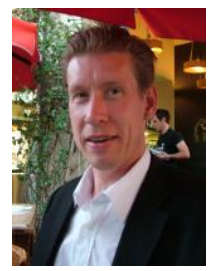

Seppo J. Sirkemaa has a Ph.D. in information systems management from Turku School of Economics at University of Turku, Finland. He has held several academic positions from researcher to research professor, and worked as a vice director of Pori Unit in Turku School of Economics at University of Turku, Finland.

Dr. Sirkemaa is also an IT consultant, and has published almost 100 academic publications. 